\title{
First isolation of Enterococcus strains in pig faeces in Turkey and determination of antibiotic susceptibilities
}

\author{
Kemal Metiner ${ }^{1}$, Mine Anğ Küçüker², Özden Büyükbaba Boral², Özdem Anğ ${ }^{4}$ \\ ${ }^{1}$ University of Istanbul, Veterinary Faculty, Department of Microbiology, Avcılar, Istanbul, Turkey \\ ${ }^{2}$ Yeni Yüzy1l University, Medical Faculty, Department of Medical Microbiology, Istanbul, Turkey \\ ${ }^{3}$ University of Istanbul, Medical Faculty, Department of Microbiology, Istanbul, Turkey \\ ${ }^{4}$ Istanbul Medical Faculty, Professor Emeritus of Microbiology, Istanbul, Turkey
}

Received October 3, 2012

Accepted April 23, 2013

\begin{abstract}
In this trial, Enterococcus strains were isolated from a total of 69 faecal samples obtained from 238 pigs ( 105 pigs $<6$ months old and $133>6$ months old) on three pig farms located in Istanbul and Tekirdag Provinces in the Marmara Region of Turkey in the summer season of 2003. Forty-seven of the isolates were determined as Enterococcus faecium (68\%), 15 isolates as Enterococcus faecalis (21.7\%), three isolates as Enterococcus gallinarum $(4.3 \%)$ and one of each as Enterococcus hirae (1.4\%), Enterococcus casseliflavus (1.4\%), Enterococcus cecorum (1.4\%) and Enterococcus sulfurens (1.4\%). In addition, antimicrobial susceptibilites of isolates were assessed through the disk diffusion method. Among $47 \mathrm{E}$. faecium isolates, 44 were determined to be resistant to erythromycin, 38 to ciprofloxacine, and three isolates were resistant to vancomycin. All E. faecalis isolates were resistant to erythromycin $(100 \%)$ and four were resistant to vancomycin (27\%). Five E. faecium (11\%) and five E. faecalis isolates (33\%) were found to exhibit intermediate resistance to vancomycin. In this study, isolates obtained from pig faeces were determined to exhibit a high rate of antimicrobial resistance. This study is the first report on isolation and determination of antimicrobial resistance of Enterocci in Turkey.
\end{abstract}

Pig, stool samples, Enterococcus spp., antibiotic sensitivity

Enterococci have emerged as important pathogens associated with serious nosocomial infections (Silverman et al. 1998; Hayes et al. 2003; Hershberger et al. 2005). They are the second most common cause of nosocomial infections and the third most common cause of nosocomial bacteraemia (Silverman et al. 1998; Peters et al. 2003). Although the role of non-human sources and reservoirs in the spread of Enterococcus strains is controversial and not clearly understood (Thal et al. 1995; Hershberger et al. 2005), animals, human foods and inanimate environments have been suspected to be sources for several resistant clinical isolates (Thal et al. 1995). It has been suggested that food animals may be a reservoir of enterococci and resistance genes capable of transferring to humans through the food chain (Arestrup et al. 2002; Hayes et al. 2003; Hershberger et al. 2005). Today, we know that antibiotic resistant bacteria are selected in the intestinal flora of animals, contaminate the foods of animal origin and transfer their resistance to other bacteria in the human gut, no matter if they are pathogenic or non-pathogenic (van den Bogaard et al. 2000). Thus, the most important reservoir for resistant bacteria and resistance genes is the intestinal flora of healthy animals and humans (van den Bogaard et al. 2000). The prevalence of antibiotic resistance found in indicator bacteria isolated from the faecal samples of humans and animals are thought to be a good indicator of the selective pressure of antibiotic usage (Knudtson et al. 1992; van den Bogaard et al. 1997; van den Bogaard et al. 2000). It has also been suggested that to determine of carriage of low level antibiotic resistance in microorganisms (especially in food animals) should be a public health goal (van den Bogaard et al. 1997; van den Bogaard et al. 2000).

Address for correspondence:

Kemal Metiner

Department of Microbiology, Veterinary Faculty

University of Istanbul, Avcilar, Istanbul

Turkey
Phone: + 902124737070

Fax: + 902124737241

E-mail: kmetiner@hotmail.com

http://actavet.vfu.cz/ 
Resistance to antimicrobials may be an inborn characteristic or it may be acquired by new genes (through e.g. conjugation) that are susceptible to antimicrobials or via mutations. The virulence of $E$. faecium species gradually increases due to resistance against commonly used antimicrobials (Lukasova et al. 2003). E. faecalis has been reported to transfer plasmids harbouring antibiotic-resistance traits to other enterococci (Marcinek et al. 1998).

Microbial resistance to antimicrobials is a serious issue worldwide, both in humans and veterinary medicine. In general, the wide use of antimicrobials is regarded as the main risk factor for the increase in antimicrobial resistance. The wide use of antimicrobials has led to development and spread of resistance genes and bacterial resistance in humans and among animals (Lukasova et al. 2003).

In Turkey, there are many studies on the epidemiology of nosocomial Enterococcus strains in humans; however, we have almost no information on the situation in animals. The aim of this study was to examine the antibiotic susceptibilities of the Enterococcus strains isolated from the faecal samples of pigs.

\section{Materials and Methods}

\section{Stool samples}

Faecal samples were collected in the 2003 summer season on three different pig farms located in Corlu (Tekirdağ), Ayazma (İstanbul) and Arnavutköy (İstanbul). The samples were obtained from a total of 238 pigs, 105 of which were under six months of age and 133 of which were older than six months. The samples (approximately $20 \mathrm{~g}$ in a plastic vial) were stored at $4^{\circ} \mathrm{C}$ and delivered to the Istanbul Medical Faculty's bacteriological laboratory on the same day.

\section{Isolation and identification of the strains}

On the day of arrival at the laboratory, the samples were diluted $\left(10^{-1}\right)$ in saline. Each of the samples was cultured through the enrichment method. Bile esculin azide (BEA) broth and BEA agar (Merck, Germany) were used for the isolation of strains. Gram staining, growth in $6.5 \% \mathrm{NaCl}$, aeskulin hydrolysis, absence of oxidase and catalase and Streptococcal group antigens were also detected using group D antiserum (Streptococcal grouping kit, Oxoid, Basingstoke, Hampshire, England), Presumptive colonies were identified using the conventional biochemical methods (Faclam et al. 1989; Faclam et al.1998; Quinn et al. 1994; Manero et al. 1999; Winn et al. 2006).

Susceptibilities of the isolated bacterial strains to antibiotics ampicillin (10 $\mu \mathrm{g})$, vancomycin $(30 \mu \mathrm{g})$, teicoplanin $(30 \mu \mathrm{g})$, gentamicin $(120 \mu \mathrm{g})$, erythromycin $(15 \mu \mathrm{g})$, ciprofloxacin $(5 \mu \mathrm{g})$ and nitrofurantoin $(300 \mu \mathrm{g})$ were investigated using the Kirby-Bauer disc diffusion method according to the CLSI criteria (CLSI document M100-S18, 2008).

\section{Results}

In total 69 Enterococcus strains were isolated from 69 faecal samples; the others (169 samples) were negative. Forty-seven (68.1\%) of the strains were identified as E. faecium, 15 strains $(21.7 \%)$ as E. faecalis, one strain $(1.4 \%)$ as E. hirae, one strain $(1.4 \%)$ as E. casseliflavus, three strains (4.3\%) as E. gallinarum, one strain (1.4\%) as E. cecorum, and one strain $(1.4 \%)$ as E. sulfurens.

When testing antibiotic susceptibilities, $44(93.6 \%)$ E. faecium and $15(100 \%)$ E. faecalis strains were resistant to erythromycin and $38(80.9 \%)$ E. faecium strains were found to be resistant to ciprofloxacin. Three (6.4\%) E. faecium and four (26.6\%) E. faecalis strains were resistant and five (10.6\%) E. faecium and five $(33.3 \%)$ E. faecalis strains were moderately resistant to vancomycin (Tables 1,2$)$.

\section{Discussion}

Sensible use of antibiotics in humans but also in animals is very important to minimize the infections caused by antibiotic resistant bacteria. Surveillance is an essential part of the antibiotic policy and should consist of regular monitoring not only of antibiotic resistance 
Table 1. Resistance patterns of the enterococci isolated from pigs

\begin{tabular}{|c|c|c|c|c|c|c|c|c|}
\hline \multirow{2}{*}{$\begin{array}{l}\text { Enterococcus } \\
\text { species }\end{array}$} & \multirow[t]{2}{*}{$\mathrm{n}=69$} & \multicolumn{7}{|c|}{ Antibiotics - No. (\%) of resistant strains } \\
\hline & & AMP & VAN & $\mathrm{TE}$ & GN & $\mathrm{E}$ & CIP & NIT \\
\hline E. faecium & 47 & - & $\begin{array}{l}3 \mathrm{R}(6.4 \%) \\
5 \mathrm{I}(10.6 \%)\end{array}$ & - & - & $\begin{array}{r}44 \mathrm{R} \\
(93.6 \%)\end{array}$ & $\begin{array}{r}38 \mathrm{R} \\
(80.9 \%)\end{array}$ & - \\
\hline E. faecalis & 15 & - & $\begin{array}{r}4 \mathrm{R}(26.6 \%) \\
5 \mathrm{I}(33.3 \%)\end{array}$ & - & - & $\begin{array}{r}15 \mathrm{R} \\
(100 \%)\end{array}$ & - & - \\
\hline E. hirae & 1 & - & - & - & - & - & - & - \\
\hline E.casseliflavus & 1 & - & - & - & - & - & - & - \\
\hline E. gallinarum & 3 & - & - & - & - & - & - & - \\
\hline E. cecorum & 1 & - & - & - & - & - & - & - \\
\hline E. sulfurens & 1 & - & - & - & - & - & - & - \\
\hline
\end{tabular}

$\mathrm{R}$ - resistant, I - intermediate resistant, AMP - ampicillin $(10 \mu \mathrm{g})$, VAN - vancomycin $(30 \mu \mathrm{g})$, TE - teicoplanin $(30 \mu \mathrm{g}), \mathrm{GN}$ gentamicin $(10 \mu \mathrm{g}), \mathrm{E}$ - erythromycin $(15 \mu \mathrm{g}), \mathrm{CIP}$ - ciprofloxacin $(5 \mu \mathrm{g})$, NIT - nitrofurantoin $(300 \mu \mathrm{g})$

Table 2. Antibiotic susceptibilities of Enterococcus isolated from pigs

\begin{tabular}{|c|c|c|c|c|c|c|c|}
\hline \multirow[t]{2}{*}{ Enterococcus species } & \multicolumn{7}{|c|}{ Antibiotics } \\
\hline & AMP & VAN & TE & $\mathrm{GN}$ & $E$ & CIP & NIT \\
\hline E. faecium $(\mathrm{n}=47)$ & $47 \mathrm{~S}$ & $3 \mathrm{R}, 5 \mathrm{I}, 39 \mathrm{~S}$ & $47 \mathrm{~S}$ & $47 \mathrm{~S}$ & $44 \mathrm{R}, 3 \mathrm{~S}$ & $38 \mathrm{R}, 9 \mathrm{~S}$ & $47 \mathrm{~S}$ \\
\hline E. faecalis $(\mathrm{n}=15)$ & $15 \mathrm{~S}$ & $4 \mathrm{R}, 5 \mathrm{I}, 6 \mathrm{~S}$ & $15 \mathrm{~S}$ & $15 \mathrm{~S}$ & $15 \mathrm{R}$ & $15 \mathrm{~S}$ & $15 \mathrm{~S}$ \\
\hline E. hirae $(\mathrm{n}=1)$ & $1 \mathrm{~S}$ & $1 \mathrm{~S}$ & $1 \mathrm{~S}$ & $1 \mathrm{~S}$ & $1 \mathrm{~S}$ & $1 \mathrm{~S}$ & $1 \mathrm{~S}$ \\
\hline E. casseliflavus $(\mathrm{n}=1)$ & $1 \mathrm{~S}$ & $1 \mathrm{~S}$ & $1 \mathrm{~S}$ & $1 \mathrm{~S}$ & $1 \mathrm{~S}$ & $1 \mathrm{~S}$ & $1 \mathrm{~S}$ \\
\hline E. gallinarum $(\mathrm{n}=3)$ & $3 \mathrm{~S}$ & $3 \mathrm{~S}$ & $3 \mathrm{~S}$ & $3 \mathrm{~S}$ & $3 \mathrm{~S}$ & $3 \mathrm{~S}$ & $3 \mathrm{~S}$ \\
\hline E. $\operatorname{cecorum}(\mathrm{n}=1)$ & $1 \mathrm{~S}$ & $1 \mathrm{~S}$ & $1 \mathrm{~S}$ & $1 \mathrm{~S}$ & $1 \mathrm{~S}$ & $1 \mathrm{~S}$ & $1 \mathrm{~S}$ \\
\hline E. sulfurens $(\mathrm{n}=1)$ & $1 \mathrm{~S}$ & $1 \mathrm{~S}$ & $1 \mathrm{~S}$ & $1 \mathrm{~S}$ & $1 \mathrm{~S}$ & $1 \mathrm{~S}$ & $1 \mathrm{~S}$ \\
\hline
\end{tabular}

$\mathrm{R}$ - resistant, I - intermediate resistant, $\mathrm{S}$ - sensitive, AMP - ampicillin $(10 \mu \mathrm{g})$, VAN - vancomycin $(30 \mu \mathrm{g})$, TE - teicoplanin $(30 \mu \mathrm{g}), \mathrm{GN}$ - gentamicin $(10 \mu \mathrm{g}), \mathrm{E}$ - erythromycin $(15 \mu \mathrm{g}), \mathrm{CIP}$ - ciprofloxacin $(5 \mu \mathrm{g}), \mathrm{NIT}$ - nitrofurantoin $(300 \mu \mathrm{g})$

but also of antibiotic use in both animal and human populations (van den Bogaard et al. 2000). Previous studies have indicated that frequent usage of a particular antibiotic in an animal population seemed to correlate not only with high prevalence of resistance to that antibiotic, but also with higher prevalence of animals with a high degree of resistance in the population (van den Bogaard et al. 2000; Arestrup et al. 2002). Therefore, numerous surveillance studies have been carried out worldwide, investigating both meat products and animal colonization.

In the study of Hayes et al. (2003) a total of 981 retail raw meat samples (chicken, turkey, pork, beef) were cultured and a total of 1357 Enterococcus strains were isolated, and E. faecium was found to be the predominant species. Hernshberger et al. (2005) investigated the antimicrobial resistance in enterococci from animal farms. They evaluated 1256 E. faecium strains and 656 E. faecalis strains from the faecal samples of cattle, swine, chickens and turkeys. None of them was vancomycin-resistant, but resistance to quinupristin/dalfopristin, gentamicin and fluroquinolones was common in various food animals (Hernshberger et al. 2005). Van den Bogaard AEJM et al. (2000) investigated the antibiotic resistance of faecal indicator bacteria in 1321 faecal samples collected from pigs at five abattoirs in the Netherlands and 100 samples from Swedish pigs. All the enterococci were found to be susceptible to amoxicillin and $4-6 \%$ of them were found to be 
resistant to high doses of gentamicin. Vancomycin resistance ranged from $24 \%$ to $46 \%$ (van den Bogaard et al. 2000). In the study of Peters et al. (2003), a total of 416 Enterococcus strains were isolated from 155 different animal origin food samples (sausage, ham, minced meat, cheese). The most frequently isolated species were E. faecalis (299 strains) and E. faecium (54 strains). Only one E. faecium strain was resistant to penicillin, whereas all strains were sensitive to glycopeptides. Similarly to our results, $74 \%$ of E. faecalis strains and all E. faecium strains were moderately resistant or resistant to erythromycin (Peters et al. 2003).

The results of a trial conducted in Denmark, Spain and Sweden to determine antimicrobial susceptibilities of samples isolated from pigs were as follows: In Denmark, 85\% of 102 E. faecalis isolates were resistant to erythromycin and $1 \%$ were resistant to gentamicin, while no vancomycin-resistant samples were isolated; $81 \%$ of $88 \mathrm{E}$. faecium isolates were resistant to erythromycin and $17 \%$ to vancomycin, while the isolates were determined to be susceptible to gentamicin; in Spain, $86 \%$ of 124 E. faecium were resistant to erythromycin, $5 \%$ to gentamicin and $2 \%$ to vancomycin; $17 \%$ of $48 \mathrm{E}$. faecalis samples isolated in Sweden were resistant to erythromycin, while they were regarded as susceptible to gentamicin and vancomycin; $6 \%$ of $18 \mathrm{E}$. faecium isolates were resistant to erythromycin and $6 \%$ to vancomycin, while all the isolates were reported to be susceptible to gentamicin (Aarestrup et al. 2002).

The antimicrobial resistance rates found in Enterococci isolates in our study are in agreement with the results of the trial conducted by Aarestrup et al. (2002). On the other hand, erythromycin resistance was detected in $100 \%$ of $15 \mathrm{E}$. faecalis isolates and in $93.6 \%$ of $44 \mathrm{E}$. faecium isolates. In contrast to gentamicin resistance in $1 \%$ of $102 \mathrm{E}$ faecali isolates in Denmark and 5\% of 124 E. faecium isolates in Spain, all the isolates in the current trial were susceptible to gentamicin.

Aarestrup et al. (2002) determined 100\% susceptibility to vancomycin in all E. faecalis isolates; however, $26.6 \%$ of E. faecalis isolates in our trial were determined to be resistant to vancomycin. The rate of vancomycin resistance among $E$. faecium isolates determined in the current trial $(6.4 \%)$ was strikingly similar to the vancomycin resistance rates of E. faecium isolated in Sweden (A arestrup et al. 2002). Utilization of similar antimicrobials for therapeutic purposes in Europe and in Turkey will lead to similar values in antimicrobial resistance rates.

Türkyılmaz et al. (2010) isolated 91 Enterococci from cats and dogs; among these isolates, only 5 E. faecium isolates exhibited intermediate resistance to vancomycin, and the authors did not determine any vanA, vanB and vanC genes; in the same trial; $30.8 \%$ of enterococci were reported to be resistant to erythromycin and $84.6 \%$ were found to be ressistant to gentamicin. In the current trial, 10 of 69 isolates $(14.49 \%)$ showed intermediate resistance to vancomycin, whereas 7 isolates $(10.14 \%)$ were determined as resistant. While no gentamicin-resistant isolates were determined, 59 of 69 enterococci isolates $(85.50 \%)$ were found to be resistant to erythromycin. The close correspondence between the erythromycin-resistance rates in our trial and in enterococci isolated from cats and dogs in our country indicate that similar antimicrobials are used in animals, and this is regarded as a major potential factor in the transmission of the agent pathogen among animals.

In a trial conducted on humans in 2005 by Kaçmaz and Aksoy (2005), 109 isolates obtained from a total of 264 urine, wound, blood, secretions and catheter samples were reported to be susceptible to vancomycin. In the current trial, 10 of 69 isolates $(14.49 \%)$ of 238 faecal samples isolated from pigs demonstrated intermediate resistance to vamcomycin, while 7 isolates $(10.14 \%)$ were regarded as resistant.

Although a number of human and food-borne isolates have been determined in various animal species in our country, we found no specific study on enterococci isolation in pig 
species. This trial is important as it is the first study conducted on isolation of enterococci in pigs.

We determined a high frequency of erythromycin and ciprofloxacin resistance among enterococci in our study. In view of our study and others, we may suggest that food animals can serve as a potential reservoir for resistant Enterococcus strains.

\section{References}

Aarestrup FM, Hasman H, Jensen LB, Moreno M, Herrero IA, Dominguez L, Finn M, Franklin A 2002: Antimicrobial resistance among enterococci from pigs in three European countries. Appl Environ Microbiol 68: $4127-4129$

Clinical and Laboratory Standards Institute (CLSI): Performance standards for antimicrobial susceptibility testing. 18th Informational Supplement. Approved Standard MS100-S18, 2008: CLSI, Wayne, PA

Faclam RR, Collins MD 1989: Identification of Enterococcus species isolated from human infections by a conventional test scheme. J Clin Microbiol 27: 731-734

Faclam RR, Teixeira LM 1998: Enterococcus. In: Lollier L, Balows A,Sussman M, editors. Topley \& Wilson's microbiology and microbial infections. 9th ed. New York: Oxford University Press, pp. 669-682

Hayes JR, English LL, Carter PJ, Proescholdt T, Lee KY, Wagner DD, White DG 2003: Prevalence and antimicrobial resistance of Enterococcus species isolated from retail meats. Appl Environ Microbiol 69: 7153-7160

Hershberger E, Oprea SF, Donabedian SM, Perri M, Bozigar P, Bartlett P, Zervos MJ 2005: Epidemiology of antimicrobial resistance in enterococci of animal origin. J Antimicrob Chemoth 55: 127-130

Kaçmaz B, Aksoy A, 2005: Antimicrobial resistance of enterococci in Turkey. Int J Antimicrob Agents 25: $535-538$

Knudtson LM, Hartman PA 1992: Routine procedures for isolation and identification of enterococci and fecal streptococci. Appl Environ Microbiol 58: 3027-3031

Lukasova J and Sustackova A 2003: Enterococci and antibiotic resistance. Acta Vet Brno 72: 315-323

Manero A, Blanch AR 1999: Identification of Enterococcus spp. with a biochemical key. Appl Environ Microbiol 65: $4425-4430$

Marcinek H, Wirth R, Muscholl- Silbernhorn A, Gauer M1998: Enterococcus gene transfer under natural conditions municipial sewage water treatment plants. Appl Environ Microbial 64: 626-632

Peters J, Mac K, Wichmann-Schauer H, Klein G, Ellerbroek L 2003: Species distribution and antibiotic resistance patterns of enterococci isolated from food of animal origin in Germany. Int J Food Microbiol 88: 311-314

Quinn PJ, Carter ME, Markey BK, Carter GR 1994: The streptococci and related cocci. In: Quinn, PJ; Carter, ME; Markey, B and Carter, GR (Eds.), Clinical veterinary microbiology. (1st. Edn.), Edinburgh, Scotland, Mosby. PP: $127-136$

Silverman J, Thal LA, Perri MB, Bostic G, Zervos MJ 1998: Epidemiologic evaluation of antimicrobial resistance in community-acquired enterococci. J Clin Microbiol 36: 830-832

Thal LA, Chow JW, Mahayni R, Bonilla H, Perri MB, Donabedian SA, Silverman J, Taber S, Zervos MJ 1995: Characterization of antimicrobial resistance in enterococci of animal origin. Antimicrob Agents Chemother 39: 2112-2115

Türkyılmaz S, Erdem V, Bozdoğan B 2010: Investigation of antimicrobial susceptibility for enterococci isolated from cats and dogs and determination of resistance genes by polymerase chain reaction. Türk J Anim Sci 34: 61-68

van den Bogaard AE 1997: Antimicrobial resistance-relation to human and animal exposure to antibiotics. J Antimicrob Chemoth 40: 453-461

van den Bogaard AEJM, London N, Stobberingh EE 2000: Antimicrobial resistance in pig faecal samples from the Netherlands (five abattoirs) and Sweden. J Antimicrob Chemoth 45: 663-671

Winn W Jr, Allen S, Janda W, Koneman E, Procop G, Schreckenberger P, Woods G 2006: Koneman's color atlas and textbook of diagnostic microbiology, Lippincott Williams and Wilkins, NewYork, pp. 700-733 